\title{
CHARACTERISTICS OF VEGETATION STRUCTURE AND ITS POSSIBLE DESTRUCTIONS AT CONSTRUCTION OF BOREHOLES FOR GAS EXPLORING AND EXTRACTION (Illustrated by Gas Yields in Irkutsk Region)
}

\author{
Alexander Sizykh ${ }^{1^{*}}$

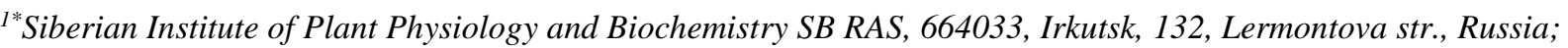 \\ *Corresponding Author Alexander Sizykh, e-mail: alexander.sizykh@gmail.com;
}

Received November 2020; Accepted December 2020; Published March 2021;

DOI: https://doi.org/10.31407/ijees11.202

\begin{abstract}
Involving of new territories not used before into different industry forms including construction of boreholes for gas exploring requires detailed revealing and comprehensive analysis of physical-geographic and environmental conditions of concrete territories. It concerns especially easily destroyable components of biota (a biome) such as vegetation cover. Underestimation of the specifics of structural-dynamic organization of phytocoenoses in concrete ecotopes can result in the destruction of vegetation up to its complete decay. Using one of gas-bearing area in Irkutsk Region, we tried to make possible characteristics of vegetation spatial stratigraphy and its responses to some impacts while constructing boring holes under existing environmental conditions.
\end{abstract}

Key words: phytocoenoses, vegetation structure, vegetation belts, ecotopes, gas-bearing area, gas exploring and extraction, Irkutsk region, East Siberia 